\title{
Perioperative Practice: Time to Throttle Back
}

\author{
Vineet Chopra, MD; Scott A. Flanders, MD; James B. Froehlich, MD, MPH; Wei C. Lau, MD; and Kim A. Eagle, MD
}

The United States spends more on health care than other nations, yet our health outcomes remain inferior to those of many countries. Change is therefore necessary. One approach to health care reform is to identify and eliminate practices associated with high cost and limited benefit. Recent research has shown that many perioperative practices meet this definition. An opportunity thus exists for rational reduction of perioperative expenditure.

Perioperative tests and treatments improve outcomes only when targeted at specific patient subsets. For example, routine perioperative stress testing provides no incremental diagnostic yield in patients at low risk for cardiac events, and indiscriminate perioperative therapy with $\beta$-blockers can increase mortality in otherwise stable patients. Thus, many "accepted" perioperative practices conflict with the evidence and can be safely discontinued while preserving outcomes and reducing costs. Implementation of the American College of Cardiology/American Heart Association perioperative guidelines ensures cost-effective management and promises the greatest benefit for our patients. Our society demands better care at lower cost; in perioperative medicine, it is time for us to throttle back.

Ann Intern Med. 2010;152:47-51.

www.annals.org

For author affiliations, see end of text.

This article was published at www.annals.org on 1 December 2009.
$M$ any current perioperative practices reinforce an unsustainable increase in health care expenditure. For instance, perioperative coronary revascularization does not improve outcomes in patients with stable coronary disease (1). Similarly, perioperative stress testing benefits far fewer patients than current implementation rates justify, and indiscriminate perioperative $\beta$-blocker therapy can cause harm when not directed to clearly defined, at-risk patient populations $(2,3)$. Perioperative medicine has thus come to represent an excellent target for health care reform.

The 2007 focused update to the joint American College of Cardiology/American Heart Association (ACC/ AHA) Guidelines on Perioperative Cardiovascular Evaluation and Care for Noncardiac Surgery (4) recommends perioperative testing and treatments only for specific cardiac conditions (Table 1). This perspective discusses how current perioperative practice conflicts with trial-derived evidence. By implementing the ACC/AHA guidelines and heeding the evidence, perioperative costs and outcomes can be favorably affected.

\section{Screening Stable Patients Before Noncardiac Surgery: A Failed Strategy}

The pathophysiology of perioperative cardiac events is complex. Catecholamine surges occur during surgery, producing elevations of heart rate and blood pressure. Heightened vasomotor reactivity and an increase in circulating coagulation factors further augment the risk for perioperative cardiovascular events (5).

It was not illogical to believe that preoperative coronary revascularization might afford protection in this situation. Working with the CASS (Coronary Artery Survival Study) investigators, we performed the largest retrospective study to date to assess whether preoperative revascularization reduced the risk for subsequent cardiac events (6). Over 10 years, 1961 patients undergoing high-risk surgery had fewer outcomes of postoperative death $(1.7 \%$ vs.
$3.3 \% ; P=0.03)$ and myocardial infarction $(0.8 \%$ vs. $2.7 \% ; P=0.02)$ after coronary bypass than medically managed coronary disease. The strategy of screening stable patients for coronary artery disease (CAD) before noncardiac surgery to identify candidates for revascularization seemed valuable, and perioperative revascularization thus emerged as a risk-reducing procedure.

In hindsight, this strategy failed for several reasons. First, the studies that suggested benefit by this approach were retrospective and were conducted almost exclusively in vascular surgery populations (7-9). Consequently, participants in these studies who underwent revascularization may have done so for indications other than the upcoming surgery itself. This was confirmed in a substudy of CASS in which perioperative coronary revascularization benefited only patients with poor left ventricular ejection fraction, peripheral arterial disease, and 3-vessel CAD (9). Additional studies also questioned the benefit of routine revascularization among patients with stable CAD. The COURAGE (Clinical Outcomes Utilizing Revascularization and Aggressive Drug Evaluation) trial (10) compared percutaneous coronary intervention and optimal medical therapy with optimal medical therapy alone. At a median follow-up of 4.6 years, COURAGE investigators found no differences between the 2 study groups with respect to death or myocardial infarction (10). The BARI 2D (Bypass Angioplasty Revascularization Investigation in Diabetes-2) study (11) also found no advantage of revascularization over intensive medical therapy among diabetics with stable CAD. The findings of CASS, COURAGE, and BARI 2D

See also:

Print

Key Summary Points. . . . . . . . . . . . . . . . . . . 48

Web-Only

Conversion of graphics into slides 


\section{Key Summary Points}

Perioperative tests and treatments improve cardiac outcomes only when targeted to clearly defined patient subsets.

Clinical trials have shown no additional benefit of cardiac testing in patients at low to moderate risk for perioperative cardiovascular events.

Perioperative coronary revascularization can cause harm and does not improve clinical outcomes, even in high-risk patients.

Perioperative $\beta$-blockers at doses titrated to heart rate and blood pressure can reduce risk in high-risk patients.

Implementing the American College of Cardiology/American Heart Association perioperative guidelines can improve clinical outcomes and reduce perioperative costs.

Perioperative practice must strive to become more evidence-based in an era of unprecedented and increasing health care costs.

emphasize that coronary revascularization beyond excellent medical therapy may offer no substantial benefit in stable patients, regardless of operative status.

Second, autopsy studies of patients with perioperative myocardial infarction frequently found that their fatal event originated from nonstenotic coronary arteries (12). Whereas we search for occlusive epicardial CAD, as many as half of perioperative myocardial events occur because of the rupture of angiographically benign "vulnerable" plaque (13). The best preoperative testing fails to reliably identify these otherwise quiescent lesions.

Third, evidence from randomized, controlled studies suggests that patients with stable coronary disease do not benefit from preoperative coronary revascularization. Investigators of the CARP (Coronary Artery Revascularization Prophylaxis) study (1) randomly assigned veterans with stable CAD who were scheduled to undergo vascular surgery to either preoperative medical therapy or coronary revascularization. After 2.7 years of follow-up, no difference in myocardial infarction or mortality was found in either group (1). Garcia and colleagues (14) recently performed a secondary analysis of CARP and confirmed that regardless of clinical risk, patients with stable CAD receiving excellent medical therapy derived no additional benefit from preoperative coronary revascularization.

Targeting coronary revascularization to patients with high-risk coronary anatomies undergoing high-risk surgery seems no more advantageous. The DECREASE-V (Dutch Echocardiographic Cardiac Risk Evaluation Applying Stress Echocardiography V) pilot study (2) hypothesized that perioperative revascularization would improve clinical outcomes in patients with stress-defined extensive CAD.
Although small, the study reported that revascularization did not change the composite end point of death or myocardial infarction at 30 days ( $43 \%$ vs. $33 \%$; odds ratio, 1.4 [95\% CI, 0.7 to 2.8 ]; $P=0.30)$ or at 1 year $(49 \%$ vs. $44 \%$; odds ratio, 1.2 [CI, 0.7 to 2.3 ]; $P=0.48$ ). A longterm follow-up study of DECREASE-V showed no delayed benefit of coronary revascularization over medical treatment for the outcomes of death or cardiac events at 2.8 years (hazard ratio, 1.35 [CI, 0.72 to $2.52 ; P=0.36])(15)$.

\section{Understanding the Failure of Perioperative REVASCULARIZATION}

Perioperative revascularization does not benefit patients with stable CAD for 2 reasons. First, our "gold standard" for detecting coronary disease and determining its severity may not be as accurate as we once thought. As studies with intravascular ultrasonography, magnetic resonance-enhanced imaging, and coronary fractional flow emerge, we recognize that coronary arteries may be diffusely diseased yet appear remarkably normal on angiographic imaging (16). Coronary disease is far more complex than the number of diseased vessels, plaque burden, or morphologic characteristics: It is the biology rather than the anatomy of coronary arteries that matters most. Coronary revascularization may not reduce the risk for coronary thrombosis, vasospasm, or plaque rupture, and these mech-

Table 1. Cardiac Conditions Warranting Evaluation,

Treatment, and Testing Before Noncardiac Surgery*

\begin{tabular}{|c|c|}
\hline Condition & Clinical Examples \\
\hline Unstable coronary syndromes & $\begin{array}{l}\text { Unstable angina (CCS class III or IV) } \\
\text { Acute myocardial ischemia or infarction } \\
\text { Recent myocardial infarction ( }>7 \mathrm{~d} \text { but } \\
\quad \leq 1 \mathrm{mo} \text { ) }\end{array}$ \\
\hline Decompensated heart failure & $\begin{array}{l}\text { NYHA functional class IV symptoms } \\
\text { New-onset heart failure or newly } \\
\text { detected heart failure } \\
\text { Deteriorating heart failure (e.g., } \\
\text { pulmonary edema, PND, weight } \\
\text { gain, rales) }\end{array}$ \\
\hline Significant atrial arrhythmias & $\begin{array}{l}\text { Symptomatic bradycardia } \\
\text { High-grade atrioventricular block } \\
\text { Mobitz type II block } \\
\text { Third-degree atrioventricular block } \\
\text { Supraventricular arrhythmias with rapid } \\
\text { ventricular rate at rest }(\geq 100 \\
\text { beats/min) } \\
\text { Atrial fibrillation with rapid ventricular } \\
\text { rate at rest ( } \geq 100 \text { beats } / \mathrm{min})\end{array}$ \\
\hline Ventricular arrhythmias & $\begin{array}{l}\text { Newly recognized or detected } \\
\text { ventricular tachycardia } \\
\text { Ventricular fibrillation }\end{array}$ \\
\hline Severe valvular disease & $\begin{array}{l}\text { Severe aortic stenosis (AVA } \leq 1.0 \mathrm{~cm}^{2} \\
\text { or mean pressure gradient } \geq 40 \\
\mathrm{~mm} \mathrm{Hg} \text { ) } \\
\text { Symptomatic mitral stenosis (associated } \\
\text { with heart failure or presyncope) }\end{array}$ \\
\hline
\end{tabular}

AVA $=$ aortic valve area; $\mathrm{CCS}=$ Canadian Cardiovascular Society, NYHA $=$ New York Heart Association; PND = paroxysmal nocturnal dyspnea.

* Data are from reference 4 . 
Class I indications (benefit $>>>$ risk) $\dagger$

Continue $\beta$-blocker therapy in patients already receiving this therapy for angina, arrhythmias, hypertension, or other ACC/AHA class I indications. (Level of evidence: C)

$\beta$-Blockers should be given to patients undergoing vascular surgery with ischemia on preoperative testing. (Level of evidence: $B$ )

Class Ila indications (benefit $>>$ risk) $\neq$

$\beta$-Blockers are probably recommended in patients undergoing vascular surgery in whom preoperative assessment identifies CAD. (Level of evidence: $B$ )

$\beta$-Blockers are probably recommended in patients undergoing vascular surgery with high perioperative risk, defined by the presence of more than 1 clinical risk factor. (Level of evidence: $B$ )

$\beta$-Blockers are probably recommended in patients undergoing intermediate-risk or vascular surgery in whom preoperative testing identifies CAD or high perioperative risk, defined by the presence of more than 1 clinical risk factor. (Level of evidence: $B$ )

\section{Class Ilb indications (benefit $\geq$ risk) $\S$}

Usefulness of $\beta$-blockers is uncertain for patients undergoing intermediate-risk No changes procedures or vascular surgery with 1 clinical risk factor. (Level of evidence: $C$ )

Usefulness of $\beta$-blockers is uncertain for patients undergoing intermediate-risk or vascular surgery with no clinical risk factors who are not currently

receiving $\beta$-blockers. (Level of evidence: $B$ )

$\beta$-Blockers titrated to heart rate and blood pressure are probably recommended for patients undergoing vascular surgery who are at high cardiac risk owing to existing $C A D$ or the finding of cardiac ischemia on preoperative testing. (Modified combined recommendation; class changed from I to Ila; wording revised)

$\beta$-Blockers titrated to heart rate and blood pressure are reasonable for patients in whom preoperative assessment identifies CAD or high cardiac risk, defined by more than 1 clinical risk factor, who are undergoing intermediate-risk surgery. (2007 recommendation remains current except for revised wording)

No changes

Class III indications (risk $\geq$ benefit)\|

$\beta$-Blockers should not be prescribed in patients who have absolute contraindications to this therapy. (Level of evidence: C)

ACC $=$ American College of Cardiology; AHA $=$ American Heart Association; CAD $=$ coronary artery disease.

* Data are from references 4 and 22.

+ Class I = Recommendation that a procedure or treatment is useful or effective; data are from multiple randomized, controlled trials.

‡ Class IIa = It is reasonable to perform the procedure or treatment listed; additional studies with focused objectives are needed.

$\S$ Class IIb $=$ Procedure or treatment may be considered; additional studies with broad objectives are needed.

\| Class III = Risk outweighs benefit; no additional studies are needed.

anisms are central to the precipitation of perioperative cardiac events.

Second, coronary revascularization has its own inherent problems. Bypassing stenotic arteries and opening occluded vessels may trigger as many events as it prevents (17). Numerous studies have shown that coronary revascularization does not reduce cardiac risk in clinically stable patients with either single-vessel or multivessel coronary disease, but it does substantially increase perioperative cost $(1,8,9,14,15)$.

\section{Routine Application of Perioperative Medical THERAPIES: A FORMULA FOR HARM}

Applying medical therapies to reduce risk in patients with stable CAD (or to those with risk factors but no documented $\mathrm{CAD}$ ) also increases perioperative peril and expense. A retrospective study of 122338 Medicare beneficiaries suggested that perioperative $\beta$-blockers were beneficial only in patients with Revised Cardiac Risk Index scores of 2 (intermediate risk) or greater and were poten- tially harmful because of bradycardia and hypotension in those with Revised Cardiac Risk Index scores of 0 or 1 (low risk) (18). The DECREASE-IV study confirmed that intermediate-risk participants $(n=533)$ who received perioperative bisoprolol titrated to heart rate and blood pressure had a lower incidence of cardiac death or myocardial infarction at 30 days than did control participants not receiving this treatment $(2.1 \%$ vs. $6.0 \%$; hazard ratio, 0.34 [CI, 0.17 to 0.67]; $P=0.002$ ) (19). In contrast, POISE (Perioperative Ischemic Evaluation Study) reported that participants receiving perioperative metoprolol succinate, $200 \mathrm{mg} / \mathrm{d}$, had improved cardiac outcomes; however, this apparent benefit was dramatically offset by increases in mortality, ischemic stroke, and sepsis compared with those receiving placebo (3).

The findings of POISE highlight the danger of administering perioperative $\beta$-blockers to intermediate- or lowrisk patients at doses not carefully titrated to hemodynamic variables (20). Perioperative cardiac event rates in patients with stable CAD are far lower than those of patients with 
unstable CAD, especially patients undergoing vascular surgery (21). The most compelling data for the use of these treatments are isolated to a strategy of therapy titrated to hemodynamic variables in high-risk patients with ischemic heart disease undergoing high-risk surgery. For these reasons, the 2009 ACC Foundation/AHA Focused Update on Perioperative Beta-Blockers (22) has modified the recommendations for perioperative $\beta$-blocker therapy (Table 2).

\section{Reducing Perioperative Costs and Improving Clinical OUtComes}

The ACC/AHA guidelines provide an algorithm that improves perioperative outcomes and reduces unnecessary testing and treatments. Through an educational program emphasizing these guidelines, our preoperative clinic improved test appropriateness and clinical outcomes while reducing cost by $50 \%$ to $75 \%$ in patients scheduled to undergo aortic surgery (23). Similarly, implementation of the guidelines in a general internal medicine preoperative clinic reduced exercise stress testing and length of stay while maintaining a low rate of complications (24). These studies illustrate how application of the guidelines can result in less "discretionary" testing or revascularization and more appropriate use of medical therapy, preserving a low rate of adverse outcomes. Physicians may struggle with implementing this evidence-based doctrine for various reasons, including legal concerns regarding perioperative cardiac events, pressure from surgical colleagues, and an inherent dependence on testing- or procedure-related income. It is thus imperative that any form of health care reform incentivize and link evidence-based care to payment. It is the quality of care, not the quantity of tests, that matters most.

\section{CONCLUSION}

Health care-related costs in the United States continue to increase in a manner disproportionate to the prevalence of existing disease. In perioperative medicine, the evidence has shown little clinical benefit and the potential for harm from current practices. We must become more evidence-driven if we are to deliver better perioperative care in a cost-effective manner. The economic climate calls for restrained testing and increased discretion in perioperative medicine. It is time for us to throttle back.

From the University of Michigan Health System, Ann Arbor, Michigan.

Potential Conflicts of Interest: Board membership: S.A. Flanders (Society of Hospital Medicine [serves as president]) Employment: S.A. Flanders (University of Michigan). Consultancies: J.B. Froehlich (Pfizer, Sanofi-Aventis). Honoraria: J.B. Froehlich (Sanofi-Aventis, Pfizer, Merck/Schering-Plough). Expert testimony: J.B. Froehlich (testified for the defense in case of malpractice regarding vascular disease diagnosis). Grants received: J.B. Froehlich (Mardigian Foundation, Blue Cross Blue Shield of Michigan, The Fibromuscular Dysplasia Society of America, W.L. Gore \& Associates). Grants pending: J.B. Froehlich (Sanofi-
Aventis). Grants received/pending: S.A. Flanders (Blue Cross Blue Shield of Michigan).

Requests for Single Reprints: Vineet Chopra, MD, University of Michigan Health System, 3119 Taubman Center, 1500 East Medical Center Drive, SPC 5376, Ann Arbor, MI 48109-5853; e-mail, vineetc $@$ med.umich.edu.

Current author addresses and author contributions are available at www .annals.org.

\section{References}

1. McFalls EO, Ward HB, Moritz TE, Goldman S, Krupski WC, Littooy F, et al. Coronary-artery revascularization before elective major vascular surgery. $\mathrm{N}$ Engl J Med. 2004;351:2795-804. [PMID: 15625331]

2. Poldermans D, Schouten O, Vidakovic R, Bax JJ, Thomson IR, Hoeks SE, et al; DECREASE Study Group. A clinical randomized trial to evaluate the safety of a noninvasive approach in high-risk patients undergoing major vascular surgery: the DECREASE-V Pilot Study. J Am Coll Cardiol. 2007;49:1763-9. [PMID: 17466225]

3. Devereaux PJ, Yang H, Yusuf S, Guyatt G, Leslie K, Villar JC, et al; POISE Study Group. Effects of extended-release metoprolol succinate in patients undergoing non-cardiac surgery (POISE trial): a randomised controlled trial. Lancet. 2008;371:1839-47. [PMID: 18479744]

4. Fleisher LA, Beckman JA, Brown KA, Calkins H, Chaikof E, Fleischmann KE, et al; ACC/AHA Task Force Members. ACC/AHA 2007 Guidelines on Perioperative Cardiovascular Evaluation and Care for Noncardiac Surgery: Executive Summary: A Report of the American College of Cardiology/American Heart Association Task Force on Practice Guidelines (Writing Committee to Revise the 2002 Guidelines on Perioperative Cardiovascular Evaluation for Noncardiac Surgery): Developed in Collaboration With the American Society of Echocardiography, American Society of Nuclear Cardiology, Heart Rhythm Society, Society of Cardiovascular Anesthesiologists, Society for Cardiovascular Angiography and Interventions, Society for Vascular Medicine and Biology, and Society for Vascular Surgery. Circulation. 2007;116:1971-96. [PMID: 17901356]

5. Devereaux PJ, Goldman L, Cook DJ, Gilbert K, Leslie K, Guyatt GH. Perioperative cardiac events in patients undergoing noncardiac surgery: a review of the magnitude of the problem, the pathophysiology of the events and methods to estimate and communicate risk. CMAJ. 2005;173:627-34. [PMID: 16157727]

6. Eagle KA, Rihal CS, Mickel MC, Holmes DR, Foster ED, Gersh BJ. Cardiac risk of noncardiac surgery: influence of coronary disease and type of surgery in 3368 operations. CASS Investigators and University of Michigan Heart Care Program. Coronary Artery Surgery Study. Circulation. 1997;96:1882-7. [PMID: 9323076]

7. Hertzer NR, Young JR, Kramer JR, Phillips DF, deWolfe VG, Ruschhaupt WF 3rd, et al. Routine coronary angiography prior to elective aortic reconstruction: results of selective myocardial revascularization in patients with peripheral vascular disease. Arch Surg. 1979;114:1336-44. [PMID: 496636]

8. Eagle KA, Coley CM, Newell JB, Brewster DC, Darling RC, Strauss HW, et al. Combining clinical and thallium data optimizes preoperative assessment of cardiac risk before major vascular surgery. Ann Intern Med. 1989;110:859-66. [PMID: 2655519]

9. Rihal CS, Eagle KA, Mickel MC, Foster ED, Sopko G, Gersh BJ. Surgical therapy for coronary artery disease among patients with combined coronary artery and peripheral vascular disease. Circulation. 1995;91:46-53. [PMID: 7805218] 10. Boden WE, O’Rourke RA, Teo KK, Hartigan PM, Maron DJ, Kostuk WJ, et al; COURAGE Trial Research Group. Optimal medical therapy with or without PCI for stable coronary disease. N Engl J Med. 2007;356:1503-16. [PMID: 17387127]

11. Frye RL, August P, Brooks MM, Hardison RM, Kelsey SF, MacGregor JM, et al; BARI 2D Study Group. A randomized trial of therapies for type 2 diabetes and coronary artery disease. N Engl J Med. 2009;360:2503-15. [PMID: 19502645]

12. Cohen MC, Aretz TH. Histological analysis of coronary artery lesions in fatal postoperative myocardial infarction. Cardiovasc Pathol. 1999;8:133-9. [PMID: 


\section{5]}

13. Dawood MM, Gutpa DK, Southern J, Walia A, Atkinson JB, Eagle KA. Pathology of fatal perioperative myocardial infarction: implications regarding pathophysiology and prevention. Int J Cardiol. 1996;57:37-44. [PMID: 8960941]

14. Garcia S, Moritz TE, Goldman S, Littooy F, Pierpont G, Larsen GC, et al. Perioperative complications after vascular surgery are predicted by the revised cardiac risk index but are not reduced in high-risk subsets with preoperative revascularization. Circ Cardiovasc Qual Outcomes. 2009;2:73-7.

15. Schouten O, van Kuijk JP, Flu WJ, Winkel TA, Welten GM, Boersma E, et al; DECREASE Study Group. Long-term outcome of prophylactic coronary revascularization in cardiac high-risk patients undergoing major vascular surgery (from the randomized DECREASE-V Pilot Study). Am J Cardiol. 2009;103: 897-901. [PMID: 19327412]

16. Mowatt G, Cummins E, Waugh N, Walker S, Cook J, Jia X, et al. Systematic review of the clinical effectiveness and cost-effectiveness of 64-slice or higher computed tomography angiography as an alternative to invasive coronary angiography in the investigation of coronary artery disease. Health Technol Assess. 2008;12:iii-iv, ix-143. [PMID: 18462576]

17. Leibowitz D, Cohen M, Planer D, Mosseri M, Rott D, Lotan C, et al. Comparison of cardiovascular risk of noncardiac surgery following coronary angioplasty with versus without stenting. Am J Cardiol. 2006;97:1188-91. [PMID: 16616024]

18. Lindenauer PK, Pekow P, Wang K, Mamidi DK, Gutierrez B, Benjamin EM. Perioperative beta-blocker therapy and mortality after major noncardiac surgery. N Engl J Med. 2005;353:349-61. [PMID: 16049209]

19. Dunkelgrun M, Boersma E, Schouten O, Koopman-van Gemert AW, van Poorten F, Bax JJ, et al; Dutch Echocardiographic Cardiac Risk Evaluation
Applying Stress Echocardiography Study Group. Bisoprolol and fluvastatin for the reduction of perioperative cardiac mortality and myocardial infarction in intermediate-risk patients undergoing noncardiovascular surgery: a randomized controlled trial (DECREASE-IV). Ann Surg. 2009;249:921-6. [PMID: 19474688]

20. Chopra V, Plaisance B, Cavusoglu E, Flanders SA, Eagle KA. Perioperative beta-blockers for major noncardiac surgery: Primum Non Nocere. Am J Med. 2009;122:222-9. [PMID: 19185285]

21. Boersma E, Poldermans D, Bax JJ, Steyerberg EW, Thomson IR, Banga JD, et al; DECREASE Study Group (Dutch Echocardiographic Cardiac Risk Evaluation Applying Stress Echocardiogrpahy). Predictors of cardiac events after major vascular surgery: Role of clinical characteristics, dobutamine echocardiography, and beta-blocker therapy. JAMA. 2001;285:1865-73. [PMID: 11308400] 22. Fleischmann KE, Beckman JA, Buller CE, Calkins H, Fleisher LA, Freeman WK, et al. 2009 ACCF/AHA Focused Update on Perioperative Beta Blockade. A Report of the American College of Cardiology Foundation/American Heart Association Task Force on Practice Guidelines. Circulation. 2009. [Epub ahead of print]. [PMID: 19884474]

23. Froehlich JB, Karavite D, Russman PL, Erdem N, Wise C, Zelenock G, et al; American College of Cardiology. American College of Cardiology/American Heart Association preoperative assessment guidelines reduce resource utilization before aortic surgery. J Vasc Surg. 2002;36:758-63. [PMID: 12368719] 24. Almanaseer Y, Mukherjee D, Kline-Rogers EM, Kesterson SK, Sonnad SS, Rogers B, et al. Implementation of the ACC/AHA guidelines for preoperative cardiac risk assessment in a general medicine preoperative clinic: improving efficiency and preserving outcomes. Cardiology. 2005;103:24-9. [PMID: 15528897]

\section{Disclosure of CONFLICTS OF INTEREST}

Annals now requires authors who submit manuscripts for consideration to complete the International Committee of Medical Journal Editors (ICMJE) conflict of interest disclosure form. This form, which is discussed further at www.icmje.org/format.pdf, is intended to facilitate detailed reporting of conflicts of interest and standardize the format of reporting across ICMJE member journals. A sample of the form is available at www.icmje.org/sampledisclosure.pdf; instructions are available at www.icmje.org/coi_disclosure.pdf. 


\section{Annals of Internal Medicine}

Current Author Addresses: Drs. Chopra and Flanders: University of Michigan Health System, 3119 Taubman Center, 1500 East Medical Center Drive, SPC 5376, Ann Arbor, MI 48109-5853.

Dr. Froehlich: Division of Cardiovascular Medicine, University of Michigan Health System, 1500 East Medical Center Drive, SPC 5853, Ann Arbor, MI 48109-5853.

Dr. Lau: Division of Cardiovascular Anesthesiology, University of Michigan Health System, Ann Arbor, MI 48109-0048.

Dr. Eagle: Cardiovascular Center, University of Michigan Health System, 1500 East Medical Center Drive, Suite 2131, SPC 5852, Ann Arbor, MI 48109-5853.
Author Contributions: Conception and design: V. Chopra, S.A. Flanders, J.B. Froehlich, K.A. Eagle.

Analysis and interpretation of the data: V. Chopra, J.B. Froehlich. Drafting of the article: V. Chopra, S.A. Flanders, K.A. Eagle.

Critical revision of the article for important intellectual content: V. Chopra, S.A. Flanders, J.B. Froehlich, W.C. Lau, K.A. Eagle.

Final approval of the article: V. Chopra, J.B. Froehlich, W.C. Lau, K.A. Eagle.

Administrative, technical, or logistic support: S.A. Flanders, K.A. Eagle. Collection and assembly of data: V. Chopra. 